\title{
Teorizando o agonismo: crítica a um modelo incompleto
}

Daniel de Mendonça ${ }^{1}$

Resumo: Em trabalhos recentes, Chantal Mouffe promove dois movimentos teóricos concomitantes. Por um lado, critica as teorias deliberativas, sobretudo os enfoques de Rawls e Habermas. Por outro lado, apresenta o modelo agonístico de democracia. A crítica de Mouffe aos deliberacionistas parte do princípio de que tais teóricos buscam a eliminação das relações de poder na política a partir do princípio racional para tomada de decisões. Para Mouffe, a eliminação do poder é uma impossibilidade, uma vez que este fundamenta a própria dimensão ontológica do político. Argumenta-se, contudo, que a alternativa da autora aos modelos deliberativos é insatisfatória, uma vez que sua proposta agonística é tão somente um princípio de ação e não propriamente um modelo teórico político estruturado. O objetivo deste paper é problematizar a proposta teórica de Mouffe, apresentando principalmente suas limitações em relação ao seu desenvolvimento.

Palavras-chave: agonismo; teoria do discurso; democracia radical; democracia deliberativa; Chantal Mouffe.

\section{Introdução}

A pós a publicação de Hegemony and socialist strategy, em 1985, por Ernesto Laclau e Chantal Mouffe, parece ter havido uma divisão do trabaIho, pelo menos tácita, entre ambos os autores, no sentido da divulgação dos seus principais aspectos teóricos e epistemológicos. Para Laclau, coube a continuidade do projeto de elaboração de uma teoria de análise do social, tendo como aspecto principal a ampliação explicativa que a categoria de hegemonia poderia proporcionar na contemporaneidade. Assim, pode-se dizer que suas obras subsequentes concentram-se, sobremaneira, no desenvolvimento e na aplicação, para análise política, de noções oriundas de diversos campos do conhecimento, tais como o marxismo, a linguística, a psicanálise, a desconstrução, o pós-estruturalismo. Seu objetivo teórico, portanto, parece estar cada vez mais claro na direção da construção de um modelo de explicação para os fenômenos sociais, ocupando a dimensão ontológica do político um lugar de destaque. Assim, seu esforço tem sido denominado de teoria do discurso ou teoria da hegemonia.
Recebimento:

09.2009

Aprovado:

05.2010

1. Doutor em Ciência Política pela Universidade Federal do Rio Grande do Sul (UFRGS). Professor do Instituto de Sociologia e Política e do Mestrado em Ciências Sociais da Universidade Federal de Pelotas (UFPel).

ddmendonca@ gmail.com 
2. Quando mencionamos aqui o "social", não estamos em absoluto falando de um social unificado ou mesmo de uma possibilidade de percebê-lo de forma totalizante. O social, segundo a teoria do discurso, não é passível de ser apreendido a partir de formas ou fórmulas gerais. Laclau é claro nesse ponto em seu texto A impossibilidade da sociedade: "hoje em dia tendemos a aceitar a infinitude do social, quer dizer, o fato de que todo sistema estrutural é limitado, que está sempre rodeado por um excesso de sentido que ele é incapaz de dominar e que, por consequência, a sociedade como objeto unitário e inteligível que funda seus processos parciais, é uma impossibilidade" (Laclau, 2000: 104), [grifos do original].
Já a tarefa empreendida por Chantal Mouffe parece direcionar-se para outro lado. A autora parte das concepções teóricas desenvolvidas em Hegemony and socialist strategy, sobretudo as categorias de antagonismo e de hegemonia, e direciona seus trabalhos posteriores não para o desenvolvimento, em conjunto com Laclau, da construção de uma analítica do social, mas lança mão de tais ferramentas teóricas no sentido da proposição de uma teoria política normativa. Mouffe critica, principalmente, os teóricos do modelo deliberativo, sobretudo Habermas e Rawls, elaborando a ideia de uma democracia agonista num contexto teórico que tem sido denominado como democracia radical e plural.

Tendo em vista essa breve notícia acerca do esforço teórico de Mouffe, este artigo objetiva discutir criticamente o seu "modelo" agonístico de democracia. Parte-se do pressuposto, portanto, de que o mesmo, na verdade, revela-se tão somente um princípio, estando muito aquém de um modelo político normativo estruturado.

Para a consecução desse objetivo, este trabalho está dividido em três seções principais. Na primeira seção, serão apontados os aspectos teóricos compartiIhados por Laclau e Mouffe, os quais embasam todo o argumento desenvolvido pela autora em suas obras posteriores. Na sequência, serão apresentados os principais pontos de crítica que Mouffe desenvolve em relação aos teóricos deliberacionistas da democracia. Na última seção, será enfocado e discutido criticamente o modelo agonístico de democracia proposto pela autora.

\section{A teoria do discurso de Laclau e Mouffe: breves apontamentos}

Como já referido, o projeto teórico de Laclau e Mouffe tem seu início, pelo menos de forma oficial, com a publicação de Hegemony and socialist strategy. Nesse trabalho, que teve uma importante repercussão, sobretudo entre os seguidores do marxismo, os autores delineiam os aspectos gerais de suas propostas teóricas posteriormente desenvolvidas. Nesta seção, sem a pretensão de apresentar globalmente os vários aspectos desenvolvidos na obra supracitada, pretende-se traçar, ao menos, seus principais contornos, principalmente aqueles que serão fundamentais para a compreensão da proposição normativa de Mouffe.

Dessa forma, inicialmente, afirma-se que a teoria do discurso tem o potencial de ser uma ferramenta de compreensão do social ${ }^{2}$, uma vez que seu próprio entendimento dá-se, nessa perspectiva, a partir da construção de ordens discursivas. Tendo como ponto de partida a centralidade das categorias de poder e de discurso - que após se desdobrarão em outras noções centrais à teoria, tais como pontos nodais, antagonismo, articulação, hegemonia, significantes vazios, populismo, dentre outras - Laclau e Mouffe articulam, como já mencionado, uma série de noções e conceitos, oriundos de várias áreas do conhecimento, 
como o marxismo, a filosofia desconstrutivista de Derrida, a psicanálise, sobretudo lacaniana, a linguística, o estruturalismo, o pós-estruturalismo. A partir de noções advindas dessas áreas, os autores constroem um aparato teórico original, inserido numa matriz contemporânea, pós-estruturalista, que contempla a contingência, a precariedade, a indeterminação e o paradoxo como dimensões ontológicas do social.

O ponto de partida de Laclau e Mouffe - ou melhor, dizendo, o ponto de partida que se entende em que deva ser iniciada uma abordagem acerca da teoria do discurso - é a sua crítica ao marxismo, entendido por esses autores como projeto teórico incapaz de dar conta da compreensão das relações sociais contemporâneas. Segundo eles, o marxismo ficou adstrito a uma concepção essencialista de sociedade, calcada, sobretudo, na lógica reducionista das relações sociais vinculadas ao antagonismo capital versus trabalho. Em oposição, Laclau e Mouffe argumentam que o que existe, efetivamente, é um complexo social formado por uma infinitude de identidades, constituídas a partir de relações discursivas antagônicas distintas do mero antagonismo de classe que, segundo a teoria do discurso, tem locus particular e não um a priori universal nesse intrincado jogo. Essa complexidade do social não é percebida e/ou alcançada pelo marxismo, o que exclui dessa corrente teórica a capacidade de análise mais refinada e pertinente dos múltiplos antagonismos sociais possíveis (Laclau e Mouffe, 1985).

Como já acima referido, a teoria de Laclau e Mouffe está fundada na ideia de que o social deve ser percebido a partir da lógica do discurso. Discurso, por sua vez, não deve ser entendido como o simples reflexo de conjuntos de textos a serem compreendidos, mas é uma categoria que une palavras e ações, que tem natureza material e não mental e/ou ideal. Discurso é prática - daí a ideia de prática discursiva - uma vez que quaisquer ações empreendidas por sujeitos, identidades, grupos sociais são ações significativas. O social, portanto, é um social significativo, hermenêutico. Não aparece como algo a ser simplesmente desvendado, desvelado, mas compreendido a partir de sua miríade de formas, das várias possibilidades de se alcançar múltiplas verdades, note-se, sempre contingentes e precárias. Assim, o real, como possibilidade de ser perscrutado, conhecido verdadeiramente como uma positividade transparente, é uma impossibilidade, tendo em vista que é significado de diversas maneiras, a partir das lentes sobredeterminadas dos sujeitos. Esta concepção de tomar o real de múltiplas formas está na base da crítica que os autores constroem ao marxismo, tendo em vista este último constituir-se não em uma teoria da sobredeterminação do social, mas numa empreitada teórica que, no limite, embasa as relações sociais a partir de uma determinação evolucionista e econômica em última instância, simplificando-as ${ }^{3}$.

Outra questão central à teoria do discurso, intimamente ligada à ideia da sobre-
3. A ideia da determinação econômica em última instância, cara ao marxismo, é a principal crítica que Laclau e Mouffe opõem à teoria althusseriana, mesmo considerando o fato de Althusser ter incorporado ao seu projeto teórico a categoria freudiana da sobredeterminação, o que seria uma forma de ampliar a possibilidade analítica da teoria marxista. Contudo, essa categoria perde seu potencial heurístico no momento em que o estruturalista francês não rompe definitivamente com o dogma marxista da determinação econômica em última instância (Laclau e Mouffe, 1985). 
4. Já se fez referência a essa ideia na nota 2. determinação, é a noção de que o próprio social não possui um sentido finalístico, ou seja, as possibilidades de significação são infinitas, sempre permeadas por relações que têm essencialmente características precárias e contingentes. Assim, Laclau e Mouffe constroem a ideia da "impossibilidade da sociedade", no sentido de que a sociedade como objeto de conhecimento pleno é impossível, uma vez que os sentidos sociais são sempre mal fechados e incompletos. Em termos de estratégia política não existe, portanto, a real possibilidade de se chegar ao "fim da história", ou seja, à vitória de um projeto político definitivo, típico sonho escatológico marxista.

Dessa forma, os sentidos sociais estão constantemente permeados pelas inconstâncias que carregam as noções de contingência e de precariedade. A contingência é inimiga da concepção teleológica da história, presente em metarrelatos e/ ou tentativas universalizantes de predição social. Pensar a partir da contingência impede-nos de tomarmos as relações sociais para além de injunções contextualizadas. Somente a partir daí, da análise stricto sensu de discursos em disputa, é que podemos produzir inferências, mas, mesmo assim, a infinitude do social pode nos pregar peças, tendo em vista que o sujeito ou a classe universal não são inexorabilidades, mas tão somente resultados de contingências históricas. Precariedade, por sua vez, revela que, mesmo que um discurso consiga fazer-se contingentemente hegemônico, esse não o será para todo o sempre, como um "fim da história". A história das relações humanas não tem propriamente um final, eis que se apresenta como uma sequência infinita de fatos, interpretações sobre esses fatos, sobre os quais não temos o direito, o poder, ou mesmo a pretensão, a partir dessa proposta teórica, de predizer cenários finais. Nesse sentido, a emancipação, entendida como a libertação completa de todas as amarras sociais, é um sonho, um ideal, um horizonte, ao mesmo tempo em que é uma impossibilidade fática.

Disse-se anteriormente que o discurso é, do ponto de vista analítico, uma categoria central para Laclau e Mouffe. No entanto, seu entendimento depende da compreensão da noção de prática articulatória. Nesse sentido, articulação é uma prática estabelecida entre elementos que, a partir de um ponto nodal, articulam-se entre si, tornando-se momentos estritamente em relação à articulação estabelecida (Laclau e Mouffe, 1985). Isso quer dizer que, no limite, esses elementos não deixam de continuar sendo elementos e que, contingencialmente, tornam-se momentos em uma determinada prática articulatória. Organizamse, portanto, tendo um ponto nodal como princípio articulador, cujo discurso é o seu resultado. Assim, insiste-se no fato de que o discurso não é uma simples soma de palavras, mas uma consequência de articulações concretas que unem palavras e ações, no sentido de produzir sentidos que vão disputar espaço no social. 
Um exemplo auxiliará na compreensão da prática articulatória acima mencionada. Um país que passa por um governo autoritário que, ao longo do tempo, é visto como corrupto, não acolhedor de demandas de variados setores da sociedade, além de, evidentemente, não-democrático, passa a sofrer uma série de resistências dos mais variados grupos sociais. Dessa forma, num primeiro momento, trabalhadores dos mais variados setores laborais, estudantes, grupos sociais os mais diversos veem que suas demandas particulares não têm sido acolhidas por esse governo inepto. Isoladamente, esses diversos grupos sociais demandam suas questões específicas e sentem-se frustrados pela não-acolhida das mesmas, quando não o são, ainda, brutalmente sufocados pelo aparelho repressor do Estado. Nesse momento inicial, segundo a perspectiva da teoria do discurso, esses grupos são vistos como elementos. São elementos, uma vez que não mantêm qualquer relação a priori entre si, mas tão somente com o frustrante governo autoritário. Num determinado instante - a partir de um discurso comum articulador de todas essas diferenças (ponto nodal), como, por exemplo, a demanda comum por democracia no contexto daquele Estado - esses grupos passam a ser momentos de uma articulação discursiva que tem como corte antagônico o regime autoritário. É decisivo, também, o entendimento de que esses elementos são diferenças articuladas, o que faz com que os mesmos tenham, ao mesmo tempo, suas demandas particulares ainda presentes, mas que, em relação à articulação que os envolve, esses cancelam suas diferenças nesse instante particular e tão somente nesse instante. Assim, é possível, inclusive, que grupos originalmente antagônicos entre si façam parte de uma mesma cadeia articulatória, tendo em vista o fato contingente de se ter um inimigo comum entre os próprios inimigos.

Tendo por base os pressupostos teóricos e epistemológicos acima, segundo Laclau e Mouffe (1985), estabelecer uma relação hegemônica significa a busca da constituição de uma ordem política. Um discurso hegemônico, nesse sentido, é essencialmente um discurso sistematizador, aglutinador. É, enfim, um discurso de unidade, de representação de diferenças.

A noção de hegemonia, para além de somente caracterizar relações de ordem, pode - do ponto de vista metodológico, para aqueles que pretendem realizar estudos sociológicos ou políticos a partir dessa categoria analítica - também auxiliar análises de períodos em que as próprias noções de ordem política ou institucional não estão claramente dadas ou devidamente hegemonizadas pelos sujeitos políticos em disputa. Utilizar, nesses casos, a ideia de hegemonia como ferramenta de análise, sugere uma importante inversão. Dessa forma, não se utiliza tal noção para descrever ou enquadrar um determinado momento político hegemônico; pelo contrário, a análise pode ser realizada para demonstrar o quão ausente é a ordem do momento em questão, ou seja, o quanto os sujeitos 
5. Nas palavras de Laclau: "hegemonizar um conteúdo equivale, por conseguinte, fixar sua significação em torno de um ponto nodal. O campo do social pode ser visto assim como uma guerra de trincheiras em que diferentes projetos políticos pretendem articular em torno de si um maior número de significantes sociais (...). A necessidade e a 'objetividade' do social depende do estabelecimento de uma hegemonia estável e os períodos de 'crise orgânica' são aqueles em que se debilitam as articulações hegemônicas básicas" (2000: 45).

6. Todas as traduções de excertos de textos originalmente publicados em inglês e espanhol foram realizadas pelo autor, para uso exclusivo neste artigo. políticos desrespeitam os fracos liames institucionais de determinados regimes políticos desacreditados por eles 5 . Nas palavras de Laclau: "numa sociedade que passa por uma profunda desorganização social, a 'ordem' pode ser vista como a inversão positiva de uma situação de anomia generalizada"6 (Laclau, 2000: 45). Contudo, podemos perguntar: o que significa uma ordem hegemônica? Como esta é produzida?

De forma mais sistemática, hegemonia é uma relação em que uma determinada identidade, num determinado contexto histórico-discursivo, de forma precária e contingente, passa a representar, a partir de uma relação equivalencial, múltiplos elementos. A ideia de hegemonia existe justamente em sua relação com a noção de falta constitutiva, presente na teoria do discurso. A falta constitutiva, por sua vez, induz à ideia de que todas as identidades se constituem sempre de forma incompleta, seja em função da própria articulação incompleta de sentidos, seja a partir da relação entre identidades, seja, ainda, por sua negação, a partir de seu corte antagônico (outra identidade que nega sua própria constituição). No sentido de Laclau e Mouffe, portanto, toda identidade vive numa constante busca de sua completude, sendo tal busca, contudo, sempre ineficaz. A hegemonia visa preencher - sempre de forma ineficaz - essa ausência de plenitude. Conforme Laclau: "entendo por 'hegemonia' uma relação em que um conteúdo particular assume, num certo contexto, a função de encarnar uma plenitude ausente" (Ibidem: 122). Daí a ideia de "ordem" hegemônica.

É importante, ainda, levarmos em consideração que o processo de constituição de uma ordem hegemônica parte sempre de um discurso particular que consegue suplementar (no sentido de supplément de Derrida), ou seja, representar discursos ou identidades até então dispersas. Esta organização ocorre a partir desse discurso centralizador, de um ponto nodal que consegue fixar seu sentido e, a partir deste, articular elementos que previamente não estavam articulados entre si. Tal fixação de sentidos, como vimos, é sempre parcial, precária e contingente, ou seja, nada pode garantir que determinado discurso ou grupo social consiga a priori articular outros discursos ou grupos sociais, como atribui o marxismo clássico ao proletariado na sua luta política. A hegemonia discursiva não é, dessa forma, uma necessidade, mas um lugar vazio, ou seja, locus de incessantes disputas entre os múltiplos discursos dispersos no campo da discursividade.

Outra categoria chave para a compreensão da lógica discursiva é a de antagonismo. No desenvolvimento da teoria do discurso, essa noção desempenha um papel central. Tal centralidade pode ser percebida no conjunto das obras de Laclau e de Mouffe, principalmente no que tange à constante referência dessa noção em seus trabalhos e o locus ontológico que ela ocupa. $\mathrm{O}$ antagonismo 
será, portanto, como se verá a seguir, elemento teórico fundamental à formulação da teoria agônica da democracia empreendida pela autora.

Dessa forma, Mouffe (2005) situa a discussão sobre o antagonismo a partir de duas noções, para ela indispensáveis, para se pensar o político. A primeira dimensão, chamada a política (politics), relaciona-se mais propriamente com um tipo determinado de trabalhos de ciência política, ou seja, aqueles referentes ao campo empírico como, por exemplo, análises eleitorais, partidárias, institucionais (a política prática, do dia-a-dia). A segunda dimensão, a dimensão do político (the political), refere-se aos trabalhos situados no campo da teoria política, cujos pesquisadores buscam averiguar "não sobre fatos da 'política', mas sobre a essência 'do político'" (Mouffe, 2005: 08); em outras palavras, o fundamento do político.

Mouffe continua enfatizando tal diferença entre os níveis da política e do político, afirmando que a primeira está inserida num nível ôntico e o político inscrevese numa dimensão ontológica. Segundo Mouffe, "isto significa que o ôntico tem a ver com as muitas práticas da política convencional, enquanto que o ontológico refere-se à própria forma como a sociedade é constituída" (Ibidem: 08-09). Essa diferença é fundamental de ser compreendida, pois em sendo a dimensão ontológica constituinte da essência do social, o antagonismo está centralmente localizado aqui, como sugere Mouffe:

Alguns teóricos como Hannah Arendt vêem o político como um espaço de liberdade e de deliberação pública, enquanto outros o vêem como um espaço de poder, conflito e antagonismo. Meu entendimento do 'político' claramente pertence à segunda perspectiva. Mais precisamente, esta é a forma como eu distingo o 'político' da 'política': por 'o político' eu entendo a dimensão do antagonismo a qual eu tomo como constitutiva das sociedades humanas, enquanto que por 'política' eu significo uma série de práticas e instituições através das quais uma ordem é criada, organizando a coexistência humana no contexto de conflitualidade provido pelo político (Ibidem: 09).

Nesse sentido, é absolutamente central entender o antagonismo presente no âmbito da teoria do discurso, tendo em vista essa categoria assumir um estatuto ontológico na construção das identidades. Assim, em linhas gerais, segundo Laclau e Mouffe, o antagonismo é entendido como a impossibilidade da constituição de um sentido objetivo, ou finalístico, de toda lógica discursiva. Já foi visto acima que a produção de sentidos por um sistema discursivo é sempre precária e contingente. Além dessas duas características já destacadas, ainda resta ver o limite produzido pelo corte antagônico. Dessa forma, o antagônico é sempre um discurso exterior; é sempre, um discurso com diferente positivi- 
dade. Nas palavras de Laclau: "o exterior é, portanto, um exterior radical sem medida comum com o interior" (Laclau, 2000: 35). O antagonismo, tomado em seu sentido mais estrito, resulta na própria impossibilidade da constituição objetiva e necessária de uma totalidade discursiva, em razão da presença de um discurso antagônico que impede essa constituição plena. Enfatiza-se, portanto, que o ponto fundamental para o entendimento da relação antagônica é que esta ocorre entre um "exterior constitutivo" que ameaça a existência de um "interior". Em outras palavras: um discurso tem bloqueado sua expansão de sentidos pela presença de seu corte antagônico.

Além desse bloqueio de expansão de sentidos de um discurso em relação ao discurso que o antagoniza (condição de impossibilidade), a teoria do discurso enfatiza que o antagonismo é também a condição de possibilidade da própria constituição discursiva. Paradoxalmente, segundo Laclau e Mouffe (1985), ao mesmo tempo em que o exterior constitutivo (discurso antagônico) ameaça a constituição do interior (discurso antagonizado), ele é também a própria condição da existência do interior, na medida em que este último se constituiu sob a ameaça da presença do primeiro.

Insiste-se, portanto, que a relação interior/exterior é antagônica, uma vez que a presença sempre constante de um impede a constituição completa do outro. Tratam-se, assim, de constituições identitárias sempre incompletas, contingentes, precárias e ameaçadas: "a presença do outro me impede de ser totalmente eu mesmo. A relação não surge de identidades plenas, mas da impossibilidade da constituição das mesmas" (Laclau e Mouffe, 1985: 125). Isso quer dizer que a produção de sentidos pelo interior discursivo está limitada pelo exterior antagônico, supondo-se assim, que o primeiro nunca poderá articular elementos do segundo sem que isso altere radicalmente suas estruturas. Dessa forma, a possibilidade de articulação com o corte antagônico seria a própria impossibilidade da estruturação discursiva.

\section{A leitura de Mouffe da tradição deliberativa}

O diálogo que Chantal Mouffe estabelece entre sua formulação teórica, a democracia radical e plural e a tradição deliberativa já vem sendo empreendido há algum tempo. Desde o seu primeiro trabalho, depois da publicação de Hegemony and socialist strategy, $O$ regresso do político, originalmente publicado em 1993, passando por seus dois livros posteriores, O paradoxo democrático, de 2000, e Sobre o político, de 2005, a autora vem lendo criticamente, sobretudo, as formulações de John Rawls e Jürgen Habermas. Para além das críticas individualizadas a qualquer um desses autores, as quais não serão aqui abordadas, Mouffe, em linhas gerais, opõe suas críticas a dois postulados deliberativos: 
a) A busca para assegurar o vínculo entre a democracia e o liberalismo, refutando todas as tentativas teóricas que insistem na natureza contraditória da democracia liberal. Ambos os autores, buscam conciliar, em última análise, segundo Mouffe (2003), a liberdade dos antigos com a liberdade dos modernos.

b) A crença compartilhada em relação à produção de uma forma de racionalidade que não seja meramente instrumental, mas que se afirme ela própria como uma dimensão normativa do social.

Evidentemente que ambos os postulados acima estão relacionados e, portanto, serão tratados conjuntamente. No entanto, um possível ponto de partida para o argumento de Mouffe (2003) pode ser a crítica ao que ela denomina de "modelo do consenso democrático", que está presente tanto na proposta de terceira via, formulada por Anthony Giddens ${ }^{7}$, a qual não será aqui tratada, como na tradição da democracia deliberativa de Rawls e Habermas. Segundo a autora, a defesa que esses teóricos fazem da possibilidade do consenso como forma de conceber a boa democracia, a sociedade bem-ordenada, denota uma incapacidade de compreensão da própria política democrática, sobretudo contemporânea, uma vez que a ênfase no consenso sustenta-se na crença de que o antagonismo possa ser efetivamente erradicado do horizonte da política. Para Mouffe, como dito acima, o antagonismo não é um mero momento político, certamente tido pelos enfoques deliberativos como negativo, pois excludente, mas a própria lógica de constituição de qualquer relação política e social.

Dizer que a dimensão do político radica-se nas relações antagônicas, como sustenta Mouffe, é pressupor que as mesmas são responsáveis pelas próprias constituições de identidades; que as relações antagônicas alteram seus conteúdos e sentidos no exato momento em que suas lutas políticas são empreendidas. Isso equivale a afirmar que as identidades nunca têm seus sentidos completamente fechados e que a luta por reconhecimento é constante e inerradicável. Em última análise, não podemos pressupor identidades prontas, pré-constituídas à luta, mas estamos, de fato, diante de identidades constituídas pelas lutas mesmas.

Assim, a identidade, os próprios indivíduos não existem dotados de direitos naturais anteriores à constituição do social: pelo contrário, a constituição das noções de direito, de justiça, de sociedade bem ordenada e mesmo a necessidade de um consenso sobre qual é a melhor forma de vida social são construções discursivas sempre contingentes e precárias. Numa palavra: o próprio consenso é um desses arranjos históricos e contingentes, fruto de um tipo de formulação política que busca hegemonizar seus conteúdos socialmente. Dito de outra forma: para além de considerar o consenso uma solução que abranja a todos os interesses, sua proposição já é, em si, uma imposição política exclu-
7. A crítica de Chantal Mouffe à proposta de Anthony Giddens está presente nas suas duas últimas obras (Mouffe, 2003 e Mouffe, 2005). 
dente, pois desconsidera outras formas de tomadas de decisão, outras maneiras de conceber o jogo democrático, pois as relega à condição de formulações políticas inferiores.

Ligada à ideia do consenso, Mouffe critica a tentativa comum de Rawls e de Habermas de conciliar a liberdade dos antigos (democracia) com a liberdade dos modernos (liberalismo). É claro que a autora leva em consideração as distintas soluções empreendidas por ambos e dá um tratamento crítico diferente para cada uma delas. Contudo, segundo ela, Rawls e Habermas concordam num ponto chave: "na crença de que através de adequados procedimentos deliberativos seria possível superar o conflito entre os direitos individuais e as liberdades, por um lado, e as demandas de igualdade e de participação popular, por outro" (Ibidem: 25).

In contrario sensu, segundo Mouffe, nenhuma das duas propostas consegue reconciliar democracia e liberalismo, uma vez que ambas as tradições são partes constituintes do que a autora tem chamado de o "paradoxo da democracia moderna", fundado justamente na sempre frustrada tentativa de conciliação entre a liberdade dos antigos e a liberdade dos modernos. Por certo, é conditio sine qua non para a democracia a convivência de ambos os institutos, mas tal convivência sempre será imperfeita, um paradoxo sempre presente. Dito de outra forma: a autora argumenta que a democracia liberal contemporânea resulta da articulação, contingente e precária, dessas duas lógicas, que são, em si, incompatíveis, e que qualquer esforço de conciliação entre ambas resultará sempre imperfeito. Isso tendo em vista que:

Por um lado, temos a tradição liberal constituída pelo império da lei, a defesa dos direitos humanos e o respeito à liberdade individual; por outro, a tradição democrática, cujas idéias principais são as de igualdade, identidade entre governantes e governados e soberania popular. Não existe uma relação necessária entre estas duas tradições distintas, somente uma imbricação histórica contingente (Ibidem: 20).

Afirma, ainda, que a busca da conciliação entre ambas gramáticas distintas apresenta outro ponto em comum para os teóricos deliberativos: a tentativa do estabelecimento de uma solução racional para as questões públicas. Opondose a tal perspectiva, a autora defende que qualquer projeto que busque uma solução racional para a questão da justiça pode ser, no limite, perigoso. Perigoso porque a solução racional pode sugerir uma sutura (fechamento) do espaço que separa a justiça do direito, justamente o espaço constitutivo da democracia moderna. Entendendo-se, aqui, que essa sutura que pode proporcionar um projeto racionalista é, de fato, impossível, uma vez que o social e suas lutas são de múltiplas possibilidades e qualquer tentativa de um arranjo racional não passa de 
mais uma tentativa ideológica de suturar o espaço social: de vê-lo como uma totalidade fragmentada à espera de sua recomposição. Em verdade, não há nada capaz de compor uma sociedade que, por essência, não se presta à composição com vistas à sua reconciliação a partir de uma melhor forma de governo ou meIhor forma de tomada de decisões públicas. Qualquer projeto político assume, conforme a perspectiva de Mouffe, condição de uma representação precária e contingente, pois que é incapaz de dominar o campo social, que sempre o transborda. A luta política, segundo a autora, é, portanto, infinita.

Neste ponto, a lógica da hegemonia é importante de ser retomada. A solução racional não é, em si, a melhor solução, mas tão somente uma das soluções possíveis numa miríade de outras possibilidades. Caso ela se tornasse uma prática corrente na política, o que parece ser factivelmente uma impossibilidade, ela o seria tendo em vista uma série de condições contingentes que a fizeram hegemônica e que relegaram outros possíveis projetos a um segundo plano.

Assim, a decisão racional, como modus faciendi da política, ao contrário do que ela própria parece sugerir, seria tão somente o resultado de uma luta, a qual, por exemplo, a racionalidade comunicativa não passaria de uma solução hegemonizada definida por uma contingência histórica falível e não propriamente pactuada a partir de pressupostos tidos como razoáveis ou mesmo minimamente desejáveis por uma série de identidades. Novamente, teríamos aqui uma operação hegemônica com a sua consequência, essa sim lógica de pressupor: a da existência de uma contra-hegemonia. Dessa forma, conforme Mouffe, devemos renunciar à ideia de um consenso político "racional", entendido por ela como "um consenso que não está baseado em nenhuma forma de exclusão" (Ibidem: 48). A exclusão é parte da dimensão antagônica da política, constitutiva das relações sociais. A racionalidade é tão somente mais um tipo de exclusão. Em suas palavras:

Apresentar as instituições da democracia liberal como o resultado de uma racionalidade puramente deliberativa é reificá-las e convertê-las em algo impossível de transformar. É negar o fato de que, igual a qualquer outro regime, a moderna democracia pluralista constitui um sistema de relações de poder e tornar o questionamento destas formas de poder como algo ilegítimo (Ibidem: 48).

Assim, para Mouffe a questão do poder é central e constitutiva das relações sociais e argumenta que, a despeito da busca de uma solução racional às questões públicas, o fechamento a outras racionalidades ou mesmo às paixões políticas reflete-se tão somente em mais uma forma de poder. Defende que o modelo deliberativo parte do pressuposto de que os indivíduos são anteriores e não constituídos pela sociedade, os quais são portadores de direitos naturais e que 
é possível compartilharem de uma mesma racionalidade operativa para as questões políticas, independentemente de suas histórias de vida, de aspectos culturais, étnicos, religiosos, como se tais fossem idiossincrasias que deveriam estar no mundo privado, como se não interviessem nas suas próprias ações políticas, nas próprias concepções ideológicas de mundo dos indivíduos. Em última análise, o modelo racional comunicativo reifica uma forma política oriunda de uma tradição ocidental que abstrai paixões e afetos como formas também legítimas de pensar o político. Em oposição, Mouffe ainda argumenta:

Diferentemente de outros projetos de democracia radical ou participativa informados por um marco racionalista, a democracia radical e plural rechaça a própria possibilidade de uma esfera pública de argumento racional não excludente em que seja possível alcançar um consenso não coercitivo. Ao mostrar que dito consenso é uma impossibilidade conceitual, não põe em perigo o ideal democrático, como alguns argumentariam. Ao contrário, protege a democracia pluralista de qualquer tentativa de fechamento. De fato, essa negativa constitui uma importante garantia de que se manterá viva a dinâmica do processo democrático (Ibidem: 49).

Assim, a importância do não fechamento da democracia pluralista deve ser aqui entendida como a sua própria possibilidade de permanência, como regime que visa dar voz e reconhecimento ao maior número possível de identidades. Prever a inclusão e a exclusão de diferenças não é, em si, excluir, mas ter em conta que qualquer arranjo político, no limite, é também excludente, inclusive o modelo deliberativo, o qual parece excluir qualquer forma de manifestação política que não seja formulada a partir de seus parâmetros "racionais". É não deixar de fora do horizonte democrático o antagonismo, como dimensão ontológica do político, inerradicável portanto. Segundo Mouffe: "em uma organização política democrática, os conflitos e os confrontos, longe de ser um sinal de imperfeição, indicam que a democracia está viva e encontra-se habitada pelo pluralismo" (Ibidem: 50). Conflitos existem e podem oxigenar a democracia, desde que mediados por princípios democráticos, no dizer de Mouffe, de um pluralismo democrático agonístico.

\section{Um modelo ou um princípio agonístico?}

Nesta última seção, serão apresentados os aspectos constituidores da teoria democrática radical e plural, a partir do que Mouffe tem chamado de "modelo agonístico da democracia". Além disso, sustenta-se aqui, contrariamente à ideia de um "modelo", que a autora, na verdade, tem enunciado até o momento, tão somente um princípio teórico norteador, sendo esta a sua principal limitação como uma teoria alternativa aos, aí sim, modelos deliberativos de Rawls e Habermas. 
Inicialmente, para caracterizar o modelo agonístico de Mouffe é necessário, novamente, fazer menção a dois aspectos ontológicos da política, segundo a sua própria abordagem. Dessa forma, Mouffe parte do princípio que é necessário sempre analisar a lógica política a partir de dois aspectos intimamente ligados e que são seus constituidores. Assim, para a melhor compreensão da natureza do político (o político entendido como a dimensão ontológica da política, que tem o caráter ôntico, como já visto), é necessário ter-se em conta as noções de poder e de antagonismo. A ideia de poder, por um lado, pressupõe sempre relações desiguais que constituem o social. Já a ideia de antagonismo, pressupõe a incapacidade da completude identitária, sempre marcada pela constante luta por posições e recursos de poder e de reconhecimento. Isso quer dizer que o poder não deve, em absoluto, ser entendido como algo dado a partir da luta entre identidades previamente constituídas, mas justamente como o elemento que constitui, que ressemantiza suas próprias identidades e sentidos (Mouffe, 2003). Dessa forma, tem-se como essência do político uma incessante luta pelo poder sempre protagonizada por identidades que, tendo em vista seus cortes antagônicos, nunca completam seus conteúdos. As consequências para a democracia, nesse sentido, não poderiam ser mais claras:

Se aceitarmos que as relações de poder são constitutivas do social, então a pergunta principal que devemos atentar para a política democrática não é a de como eliminar o poder, mas a de como constituir formas de poder mais compatíveis com os valores democráticos (Ibidem: 113).

Assim, deve-se ter claro que as relações sociais são essencialmente conflitivas e que todos os intentos de eliminar o poder e o antagonismo das relações humanas, como parecem supor os modelos deliberativos, estarão fadados ao fracasso. O que parece importante, na acepção teórica de Mouffe, é como construir mecanismos institucionais que visem principalmente "domesticar" as relações antagônicas entre identidades que visam hegemonizar sentidos no espaço social, visto pela autora como um espaço discursivo.

Nesse ponto, é salutar retomar a distinção entre a dimensão ontológica e ôntica presentes no argumento de Mouffe para, a partir daí, estabelecer as bases para o seu pluralismo agonístico. Tal distinção entre ambas as dimensões é realizada desde a diferenciação entre a política e o político, estando a primeira diretamente ligada à política prática, instituições e formas de organização pragmática das relações sociais. Assim, a política assume o caráter ôntico, o da política do dia-a-dia. Já o político representa a própria dimensão antagônica inerente às relações humanas, presentes em todas as práticas políticas, pois que é constitutiva das mesmas. Assim, o político está num plano ontológico, ou seja, como aquilo que está na essência, na constituição, na forma, portanto refere-se a como as 
8. Paixões, conforme Mouffe, referem-se às várias forças afetivas as quais estão na origem de formas coletivas de identificações (Mouffe, 2005: 24). relações políticas, sem exceção, devem ser pensadas. Nesse sentido, qualquer modelo teórico-normativo, se tem por objetivo ser factível, deveria levar em consideração não a erradicação das relações de conflito, mas a melhor forma de institucionalizá-las, uma vez que é impossível a superação das relações desiguais de poder e do antagonismo.

Assim, segundo Mouffe, o que é central para a política democrática, ou o que deveria sê-lo, tendo em vista essa percepção ontológica do político, é a busca da construção de um modelo que faça com que os inimigos deixem de ser percebidos como tais e, portanto, como aqueles que devem ser subsumidos, eliminados. É necessário que se busque meios que transformem os inimigos em adversários, o que na acepção de Mouffe produz importantes consequências. Um inimigo, como já referido, é alguém a quem deve-se destruir, com o qual se estabelece uma relação antagônica no sentido mais estrito do termo. Um adversário, por outro lado, é alguém com cujas ideias não se concorda, mas o mesmo tem o direito de defendê-las e esse direito não deve ser questionado. Nesse sentido, Mouffe postula:

Introduzir a categoria do 'adversário' requer fazer mais completa a noção de antagonismo e distinguir duas formas diferentes nas quais pode surgir esse antagonismo, o antagonismo propriamente dito e o agonismo. O antagonismo é uma luta entre inimigos, já agonismo é uma luta entre adversários. Por conseguinte, podemos voltar a formular nosso problema dizendo que, visto da perspectiva do 'pluralismo agonístico', o objetivo da política democrática é transformar o antagonismo em agonismo (Ibidem: 116).

Conforme Mouffe, uma diferença essencial entre sua proposta teórica e os modelos deliberativos é que, para o "pluralismo agonístico", o objetivo da política democrática não é a eliminação das paixões ${ }^{8}$, dos próprios interesses da esfera pública, para aí se buscar um consenso racional, mas justamente o contrário: é tarefa da democracia construir mecanismos que sejam capazes de mobilizar, dar existência a tais paixões e interesses dentro de princípios e regras democráticas, ou seja, que se assegure a existência conflitiva da dimensão humana, que é inerradicável, mas que transforme os inimigos em adversários dentro de regras estabelecidas pelo jogo democrático. Nas suas próprias palavras:

Uma democracia que funcione corretamente exige o vibrante enfrentamento das posições políticas democráticas. Se isso é omitido, existe o perigo de que esta confrontação democrática seja substituída por uma confrontação entre outras formas de identificação coletiva, como sucede no caso da política de identidade. Uma excessiva ênfase no consenso, unida ao rechaço da confrontação, conduz à apatia e ao distanciamento com 
relação à participação política. Ainda pior, o resultado pode ser a cristalização das paixões coletivas em torno de questões que não podem ser resolvidas mediante um processo democrático e a explosão dos antagonismos pode deixar em pedaços os próprios fundamentos da civilidade (Ibidem: 117).

Assim, conforme Mouffe, o objetivo da democracia não deveria ser a busca de um consenso racional no âmbito de uma esfera pública. É importante que a autora não nega a possibilidade de se alcançar o consenso sobre determinadas questões e em determinados contextos, mas tal será sempre um resultado contingente de uma hegemonia provisória acerca de uma questão. Ainda mais, para Mouffe, a defesa de que o poder possa ser substituído por um debate racional em que, a partir daí, se poderia chegar a algum tipo de legitimidade pública, "são ilusões que podem por em perigo as instituições democráticas" (Ibidem: 117). Isso porque toda a forma de poder, inclusive o consenso racional, pressupõe exclusões e a tentativa de sutura final do social, a qual parece propor o modelo deliberativo, impede que outras formas políticas tenham efeito.

Um exemplo interessante de entendimento do pluralismo agonístico presente nas democracias modernas é trazido por Mouffe a partir da análise de Canetti em Crowds and Power, no momento em que esse autor fala da natureza do sistema parlamentar. Segundo Canetti, a democracia e o sistema parlamentar não devem ser vistos como um estágio evolutivo da humanidade no sentido em que ocorre entre os contendores a renúncia da guerra e da morte como meios de decisão. Os seres humanos não trocaram, portanto, a batalha campal por um meio racional de decisão, pela livre razão pública quando instituíram os parlamentos. Conforme Canetti, citado por Mouffe (2005: 23):

Ninguém nunca realmente acreditou que a decisão da maioria é necessariamente mais sábia por ter recebido o maior número de votos. É a vontade contra a vontade como na guerra. Cada um está convencido que o direito e a razão estão do seu lado. A convicção vem facilmente e o propósito do partido é, precisamente, manter este desejo e esta conviç̧ão vivos. 0 membro de um partido que perdeu a votação aceita a decisão da maioria, não porque ele deixou de acreditar no seu próprio ponto de vista, mas simplesmente ele admite a derrota.

É a partir deste exemplo de Canetti que se passa a estabelecer algumas críticas ao pluralismo agonístico de Mouffe. Resumindo alguns pontos importantes de sua perspectiva, tem-se:

a) as relações de poder e de antagonismo são constituidoras de todas as relações políticas; 
b) existem duas dimensões ou dois níveis em que as questões políticas devem ser levadas em consideração: a política (dimensão ôntica) e o político (dimensão ontológica);

c) qualquer tentativa de estabelecer um consenso permanente acerca de questões públicas é, no limite, impossível, ou seja, não passará de um arranjo hegemônico precário, histórico e contingente;

d) como as relações antagônicas perpassam todas as relações humanas, a tarefa da democracia contemporânea está em transformar as relações antagônicas stricto sensu, ou seja, entre inimigos que querem se destruir, em relações agônicas, entre adversários que lutam aceitando alguns parâmetros comuns na disputa.

O exemplo de Canetti ilustra muito bem a domesticação agonística das disputas sociais. A arena parlamentar foi a maneira concebida para, sob uma forma regulada, os antes inimigos, agora adversários, fazerem valer seus interesses e paixões. A derrota não é vista como uma derrota final. Há sempre a possibilidade de uma nova disputa, de uma virada no jogo e isso é o que dá legitimidade ao sistema parlamentar. $O$ que, contudo, ficam mantidas são as regras do jogo, sobretudo as que dizem respeito ao fato de que a vitória de um grupo, ou partido, deve ser reconhecida pelo outro, não no mérito, uma vez que a vitória não é fruto de um consenso entre as partes, ou mesmo de um próprio convencimento racional de um pelo outro, mas na forma como ela foi obtida, ou seja, pela maioria numérica dos votos de quem legitimamente está apto para decidir.

Apesar de concordar com os principais aspectos concernentes à posição teórica de Mouffe, entende-se que é um tanto improvável considerar seu autodenominado "modelo" pluralista agonístico como tal, ainda mais se comparado com os modelos deliberativos de Rawls e Habermas. Rawls e Habermas apresentam seus modelos, certamente, num nível altamente abstrato e de difícil possibilidade fática, e desenvolvem-nos a partir de uma série de condições e formas de execução. É possível ter um "aspecto visual" de suas propostas, pois, enfim, são realmente modelos políticos normativos. Isso não ocorre no caso de Mouffe e esse ponto parece ser o que mais fragiliza seu argumento.

Apesar de o pluralismo agonístico já estar sendo apresentado pela autora desde o seu penúltimo livro, $O$ paradoxo democrático, não avança muito além do que ela própria chama de transformar as relações antagônicas em agônicas num contexto político democrático sempre dominado pelas questões de poder e de antagonismo. Seu argumento desconstrutivista ao modelo deliberativo é potente, sem dúvida. Contudo, quando chega no momento de ela própria exercer seu papel normativo, sua empresa emperra. 
Assim, Mouffe não apresenta propriamente um modelo teórico visando superar o deliberacionismo, o qual ela considera como sendo hegemônico no atual contexto da teoria política. Ela se resume a repetir, aí sim, seu princípio agônico no contexto democrático. Trata-se, portanto, de um modelo incompleto. Questões como, por exemplo: como criar ou mesmo aumentar espaços agonísticos? Como tratar os excluídos da arena agonística num sistema democrático, tendo em vista que a dimensão do político sempre prevê exclusões? Enfim, como aumentar o nível de participação e de inclusão de identidades a partir do modelo agonístico?

Não é objetivo deste trabalho responder a tais questões, mas sim problematizá-las. Nesse sentido, em relação à primeira, a autora afirma que é necessário transformar as relações antagônicas em agônicas, o que é um ensaio normativo em direção da radicalização da democracia. Dizer isso significa criar novas regras, espaços de lutas para que efetivamente se possam substituir os pontos de antagonismos nas sociedades por locais, instituições que efetivamente passem a regular conflitos agônicos. O exemplo do parlamento de Canetti é certamente a efetivação de um locus regulado de disputa agônica e não há dúvida que a efetivação de uma política como esta só é possível no contexto democrático. $\mathrm{O}$ agonismo não tem lugar em qualquer outro regime, pois pressupõe sempre uma pluralidade de princípios ideológicos em constante disputa. O problema é que Mouffe não menciona como isso poderia ter efeito; ela não transpõe o limite dessa enunciação.

As questões da natureza política em prever sempre uma forma de exclusão e o nível de participação e de inclusão de identidades são outros pontos na formulação de Mouffe que merecem atenção e serão tratados conjuntamente. Desse modo, a autora afirma que todas as relações políticas geram necessariamente exclusões, inclusive a possibilidade mesma de consenso racional proposto pelos modelos deliberativos. Continua afirmando que possibilidade de exclusão identitária atual pode ser vista como a sua possibilidade de inclusão no futuro, uma vez que é fundamental manter o espaço político sempre aberto a novas possibilidades. Essa possibilidade de operação de inclusão/exclusão de direitos a uma pluralidade de interesses e de identidades só tem efeito a partir de rearranjos hegemônicos, justamente possibilitados pela abertura do social. Contudo, parece evidente que a possibilidade de inclusão deva ser precedida por uma luta política por parte daquele que está socialmente excluído. Mas estar excluído pode significar nem sequer ter os meios para lutar pela inclusão. Estar excluído pode significar a geração de uma apatia política, tomando-se por base um sentimento de que é inútil lutar.

Parece que a tarefa central do pluralismo agonístico de Mouffe é a de constituirse, de fato, como um modelo teórico passível de ser testado. No entanto, até o momento restringe-se à desconstrução, aí sim, do modelo deliberativo baseado 
no consenso. Mas ainda está no nível da enunciação de princípios, os quais são de duas ordens. Os princípios de primeira ordem dizem respeito à própria essência do político, ou seja, fundada nas relações de poder e no antagonismo. Como elementos ontológicos, devem ser levados em consideração para toda e qualquer teoria política calcada no princípio da realidade. O princípio de segunda ordem é a ideia central da teoria agônica, ou seja, a transformação das relações antagônicas em agônicas, a substituição da categoria de inimigos pela de adversários, o que é muito interessante, sem dúvida. Mas o seu modelo incompleto pára por aí. Mouffe não desenvolve mais normativamente o pluralismo agonístico, no sentido da proposição de instituições, quem sabe um novo tipo de parlamento que trate de questões políticas culturais originalmente não econômicas, arenas de lutas institucionalizadas, etc.

Mouffe enuncia um princípio que abre várias possibilidades para se pensar a democracia contemporânea. Entretanto, como o dia-a-dia da política ocorre na dimensão ôntica, é preciso pensar instituições ou práticas políticas efetivas que façam valer o princípio agônico. Talvez esse seja ainda um capítulo a ser escrito pela autora ou por aqueles que aceitarem o desafio.

Abstract: In recent works, Chantal Mouffe presents, at the same time, two theoretical movements. In the one side, she criticizes deliberative theories, above all Rawls and Habermas accounts. In the other side, she presents the agonistic model of democracy. The Mouffe's critic to the deliberationists starts from the principle that these researchers aim to eliminate power relations from politics, changing them by a rational principle for decision making. For Mouffe, power elimination is impossible, once power ground the very ontological dimension of the political. In this paper, it argues, however, that the Mouffe's alternative to the deliberative models is unsatisfied, once her agonistic purpose is only an action principle and not necessarily a political theoretical model structured. The aim of this paper is to discuss Mouffe's theoretical purpose, presenting mainly its limitations in relation to its development.

Keywords: Agonism; Discourse Theory; Radical Democracy; Deliberative Democracy; Chantal Mouffe.

\section{Referências}

LACLAU, E.; MoufFE, C. (1985) Hegemony and socialist strategy: towards a radical democratic politics. Verso, London.

. (2000) La impossibilidad de la sociedad. Nueva Visión, Buenos Aires,

$2^{\mathrm{a}} \mathrm{ed}$. 
Mouffe, C. (1996) O regresso do político. Gradiva, Lisboa. . (2003) La paradoja democrática. Gedisa Editorial, Barcelona. . (2005) On the political. Routledge, New York. 